\title{
Longitudinal changes in placental biomarkers in women with early versus late placental dysfunction
}

Citation for published version (APA):

Hendrix, M. L. E., Palm, K. C. M., Van Kuijk, S. M. J., Bekers, O., Spaanderman, M. E. A., Bons, J. A. P., \& Al-Nasiry, S. (2019). Longitudinal changes in placental biomarkers in women with early versus late placental dysfunction. Hypertension in Pregnancy, 38(4), 268-277.

https://doi.org/10.1080/10641955.2019.1668948

Document status and date:

Published: 02/10/2019

DOI:

10.1080/10641955.2019.1668948

Document Version:

Publisher's PDF, also known as Version of record

Document license:

Taverne

Please check the document version of this publication:

- A submitted manuscript is the version of the article upon submission and before peer-review. There can be important differences between the submitted version and the official published version of record.

People interested in the research are advised to contact the author for the final version of the publication, or visit the DOI to the publisher's website.

- The final author version and the galley proof are versions of the publication after peer review.

- The final published version features the final layout of the paper including the volume, issue and page numbers.

Link to publication

\footnotetext{
General rights rights.

- You may freely distribute the URL identifying the publication in the public portal. please follow below link for the End User Agreement:

www.umlib.nl/taverne-license

Take down policy

If you believe that this document breaches copyright please contact us at:

repository@maastrichtuniversity.nl

providing details and we will investigate your claim.
}

Copyright and moral rights for the publications made accessible in the public portal are retained by the authors and/or other copyright owners and it is a condition of accessing publications that users recognise and abide by the legal requirements associated with these

- Users may download and print one copy of any publication from the public portal for the purpose of private study or research.

- You may not further distribute the material or use it for any profit-making activity or commercial gain

If the publication is distributed under the terms of Article $25 \mathrm{fa}$ of the Dutch Copyright Act, indicated by the "Taverne" license above, 


\section{Longitudinal changes in placental biomarkers in women with early versus late placental dysfunction}

Manouk L. E. Hendrix, Kirsten C. M. Palm, Sander M. J. Van Kuijk, Otto Bekers, Marc E. A. Spaanderman, Judith A. P. Bons \& Salwan Al-Nasiry

To cite this article: Manouk L. E. Hendrix, Kirsten C. M. Palm, Sander M. J. Van Kuijk, Otto Bekers, Marc E. A. Spaanderman, Judith A. P. Bons \& Salwan Al-Nasiry (2019) Longitudinal changes in placental biomarkers in women with early versus late placental dysfunction, Hypertension in Pregnancy, 38:4, 268-277, DOI: 10.1080/10641955.2019.1668948

To link to this article: https://doi.org/10.1080/10641955.2019.1668948

View supplementary material ¿

曲 Published online: 27 Sep 2019.

Submit your article to this journal $₫$

III Article views: 221

View related articles $₫$

View Crossmark data

Citing articles: 1 View citing articles $₫$ 


\title{
Longitudinal changes in placental biomarkers in women with early versus late placental dysfunction
}

\author{
Manouk L. E. Hendrix (1) ${ }^{a}$, Kirsten C. M. Palma, Sander M. J. Van Kuijk ${ }^{b}$, Otto Bekers ${ }^{c}$, Marc E. A. Spaanderman ${ }^{a}$, \\ Judith A. P. Bons', and Salwan Al-Nasiry ${ }^{\mathrm{a}}$ \\ ${ }^{a}$ Department of Obstetrics \& Gynecology, Maastricht University Medical Centre (MUMC+), Maastricht, The Netherlands; ${ }^{b}$ Department of \\ Clinical Epidemiology and Medical Technology Assessment (KEMTA), Maastricht University Medical Centre(MUMC+), Maastricht, The \\ Netherlands; 'Central Diagnostic Laboratory, Maastricht University Medical Centre (MUMC+), Maastricht, The Netherlands
}

ABSTRACT

Objective: To evaluate longitudinal changes of angiogenic biomarkers in early- (EO-PD) versus late-onset (LO-PD) placental dysfunction.

Methods: Serum PIGF and sFlt-1 measured at different intervals in EO-PD $(n=43), L O-P D(n=31)$ and controls ( $n=133$ ).

Results: sFlt-1/PIGF ratio was higher at 16 weeks (30.6 vs 17.5), 20 weeks (29.3 vs 8.9 ) and 30 weeks (16.6 vs 6.7) in EO-PD vs controls (all $p<0.05$ ), but not in LO-PD. Longitudinal changes for all intervals had higher AUC than single measurements.

Conclusion: Longitudinal biomarker change between 12 and 30 weeks could improve prediction of EO-PD compared to single measurements.

\section{ARTICLE HISTORY}

Received 4 April 2019

Accepted 8 September 2019

KEYWORDS

Early Pregnancy

Complications; Eclampsia;

HELLP; High-Risk Pregnancy; Pregnancy induced

Hypertension; Placenta;

Preeclampsia; Fetal Growth

Restriction

\section{Introduction}

The phenotypes of placental dysfunction, especially those affected by defective deep placentation, are significantly related to maternal and perinatal mortality and morbidity (1-8). Adequate screening to identify pregnant women at risk of developing placental dysfunction could help improve the efficacy and quality of antenatal care, thus improving maternal and perinatal outcomes (9-11). Early-onset placental dysfunction is believed to arise from inadequate trophoblastic invasion, that leads to insufficient remodeling of the spiral arteries affecting placental perfusion. This placental malperfusion is associated with a relative decrease in angiogenesis-related factors (e.g., Placental growth factor (PlGF)) and a relative increase in anti-angiogenesis factors (e.g., soluble fms-like tyrosine kinase 1 (sFlt-1)) (12). Placental growth factor (PlGF) is a pro-angiogenic factor predominantly expressed in placental trophoblast and binds to VEGF-receptor or fms-like tyrosine-1 (Flt1), thereby enhancing the pro-angiogenic action of VEGF-A. Besides this membrane-bound receptor form, Flt-1 also exists in a soluble form (sFlt-1), which is mainly secreted by the placenta and scavenges VEGF and PIGF, thereby lowering circulating levels of unbound VEGF and PlGF (13-15). The placenta is the major source of sFlt-1 during pregnancy; however, in non-pregnant women, sFlt-1 is also produced in small amount by endothelial cells and monocytes (16). Although the exact source of increased sFlt- 1 in the circulation is not yet determined, rapid decline in sFlt1 levels after delivery and the upregulation of placental sFlt1 mRNA strongly suggests a placental origin of the sFlt1 (17).

Late-onset preeclampsia is thought to be associated with trophoblast dysfunction due to villous overcrowding in term placentas, leading to diminished intervillous perfusion and increased hypoxia (18). It seems that the placenta outgrows the capacity of uterine vasculature to support the increasing demands of the term placenta (19-21,22). Another theory is that placental dysfunction, mainly in late-onset disease, is an epiphenomenon caused by failure of the maternal cardiovascular system to adapt to pregnancy (23). There is an increase in cardiovascular load on the maternal heart and vasculature throughout pregnancy, with an accompanying increase in shear stress and endothelial activation. Late-onset preeclampsia has been linked to preexisting maternal conditions that could affect endothelial integrity by a systematic maternal inflammatory response, consequently resulting in endothelial dysfunction (24-26).

Many obstetric syndromes have been associated with defective deep placentation. Most studies investigated the relation of serum level sFlt-1 and PlGF in maternal

CONTACT Manouk L. E. Hendrix manouk.hendrix@mumc.nl D Department of Obstetrics and Gynecology, Maastricht University Medical Centre, PO Box 5800, Maastricht 6202 AZ, The Netherlands 
placental syndrome, mostly preeclampsia. Few studies looked at both maternal and fetal complications $(27,28)$. Previous studies of these biomarkers demonstrated no significant difference in the maternal blood level of sFlt1 between preeclampsia and control pregnancies until the second half of pregnancy, whereas PIGF already differed substantially in the first trimester (29-32). Only a few studies have evaluated longitudinal changes during the different trimesters in sFlt- 1 and PlGF and the results are variable $(27,28,32-36)$ and could be explained by different subtypes of placental dysfunction.

Many experts consider onset of placental dysfunction before 34 weeks as an indicator of a severe subtype related to placental bed pathology, while onset after 34 weeks has usually a milder course and is more related to placental capacity $(22,37)$. Angiogenesis-related biomarkers could possibly discriminate between these subtypes of placental dysfunction. However, there is a lack of literature on longitudinal changes in biomarker levels during pregnancy in early versus late-onset placental dysfunction.

The first objective of this study was to assess whether the subtypes of placental dysfunction (early versus lateonset) are associated with a change in Placental Growth Factor (PlGF) and soluble Fms-like tyrosine kinase-1 (sFlt-1) levels. And second to assess whether the performance of screening by these biomarkers is improved by calculating the longitudinal biomarker changes compared to single timepoint biomarker measurements.

\section{Materials and methods}

\section{Study design and participants}

We performed a retrospective cohort study in women with singleton pregnancies between January 2015 and December 2017. Participants were recruited from a monitoring program at the department of obstetrics at the Maastricht University Medical Centre, where high-risk women structurally undergo cardiovascular measurements at 12,16, 20 and 30 weeks of pregnancy. High risk was defined as having pre-existent hypertension, diabetes mellitus, an auto-immune disease or a previous pregnancy complicated by hypertension, preeclampsia, HELLP-syndrome, eclampsia and/or related fetal complications including delivery of a small for gestational age neonate, stillbirth or placental abruption. All women with singleton pregnancies at high risk of developing placental dysfunction based on obstetric history and/or medical history were included. We excluded 154 pregnant women, who had missed more than two visits (at 12, 16, 20 or 30 weeks) ( $\mathrm{n}=149)$, had multiple pregnancies $(n=4)$ or multiple congenital disorders $(n=1)$.
Relevant maternal baseline characteristics, like date of birth, method of conception, cigarette smoking during pregnancy, medical and obstetric history including parity and obstetric complications were recorded. Patients who refused using their records were excluded in this study. The study protocol was approved by the medical ethical committee of the Maastricht University Medical Center (17-4-0.15.1/ ab). All procedures were in accordance with institutional guidelines and adhered to the principles of the Declaration of Helsinki and Title 45, U.S. Code of Federal Regulations, Part 46, Protection of Human Subjects (revised 13 November 2001, effective 13 December 2001).

\section{Placental dysfunction}

Early-onset placental dysfunction was defined as placenta-mediated complications diagnosed before 34 weeks: early-onset fetal growth restriction (FGR), early-onset preeclampsia/eclampsia, preeclampsia in combination with HELLP syndrome (hemolysis, elevated liver enzyme levels, and low platelet levels) and placental abruption. Late-onset placental dysfunction was defined as preeclampsia or pregnancy-induced hypertension (PIH), diagnosed after 34 weeks of gestation.

Preeclampsia (PE) was defined according to the guidelines of International society for the Study of Hypertension in Pregnancy (38). In normotensive women at baseline, PE was defined as the development of hypertension with proteinuria. When a woman was suspected of developing hypertension, blood pressure was recorded for a period of $30 \mathrm{~min}$ at 3-min intervals using a semiautomatic oscillometric device in half-sitting position. Median values of 9 subsequent recordings were used for analysis. Hypertension was then defined as a median systolic blood pressure equal to or greater than $140 \mathrm{mmHg}$, and/or a diastolic blood pressure equal or greater than $90 \mathrm{mmHg}$. The diagnosis of proteinuria required excretion of albumin/creatinine ratio of more than $30 \mathrm{mg} / \mathrm{mmol}$, without evidence of a urinary tract infection. Chronic hypertension was defined by documentation of hypertension and/or required antihypertensive-drug therapy by medical records. In patients with chronic hypertension, PE was defined as new-onset proteinuria after gestation. FGR was defined in accordance with the national standard, as an abdominal circumference (AC), or an estimated fetal weight $<10$ th percentile, measured during routine ultrasound scans (39). 


\section{Angiogenesis-related biomarkers}

Blood samples were analyzed in a certified laboratory using commercially available kits by personnel who were unaware of the outcome of the pregnancy. Measurements of sFlt-1 and PIGF assays were performed according to the manufacturer's instructions on the fully automated BRAHMS KRYPTOR compact PLUS system (ThermoFisher Scientific, Hennigsdorf, Germany). Both assays are homogeneous sandwich immunoassays based on the Time Resolved Amplified Cryptate Emission (TRACE) technology. The PlGF assay has an analytical measuring range of $6.7-7000 \mathrm{pg} / \mathrm{ml}$ and the sFlt-1 assay has an analytical measuring range of $29-90.000 \mathrm{pg} / \mathrm{mL}$.

The limit of detection (LOD) is $3.6 \mathrm{pg} / \mathrm{ml}$ and $22 \mathrm{pg} / \mathrm{ml}$ for PlGF and sFlt-1, respectively. The functional assay sensitivity (FAS) (inter-assay precision of $20 \%$ ) is $6.7 \mathrm{pg} /$ $\mathrm{ml}$ and $29 \mathrm{pg} / \mathrm{ml}$ for PlGF and sFlt-1, respectively. The limit of quantitation (with total error (imprecision and bias) at $40 \%$ ) is $6.9 \mathrm{pg} / \mathrm{ml}$ and $34 \mathrm{pg} / \mathrm{ml}$ for PlGF and sFlt1 , respectively. The LOD and LOQ have been determined following CLSI EP17-A guideline (Protocols for Determination of Limits of Detection and Limits of Quantitation). The FAS have been determined following CLSI EP05-A2 guideline (Evaluation of Precision Performance of Quantitative Measurement Methods). Measurements were performed in singleton. Quality control samples were included in each run. Total precision for both assays displayed CVs of $<10 \%$.

All patients had serial measurements of PlGF and sFlt1 and the corresponding ratio was calculated. We evaluated the longitudinal change in serum concentrations of sFlt-1, PlGF and sFlt-1/PlGF ratio at different intervals $(12-16,12-20,12-30,16-20,16-30$, and $20-30$ week gestation).

\section{Statistical methods}

Normally distributed baseline characteristics are presented as mean with standard deviation, not normally distributed data are presented as median. Categorical variables are depicted as percentages $(n / N)$. Maternal baseline characteristics were compared between groups using analysis of variance (ANOVA) or Kruskal-Wallis test for continuous variables and Fisher's exact test or chi-square test for categorical variables. An unpaired $t$-test was used to analyze differences between groups with normally distributed data. For non-normal distributed data, we used the Mann-Whitney $U$ test.

We tested differences in serum biomarker levels at the different time intervals between the reference group and each outcome group separately: early-onset placental dysfunction and subdividing the late-onset placental dysfunction group in late-onset $\mathrm{PE}$ and $\mathrm{PIH}$, with one way-ANOVA or the Kruskal-Wallis test.

Repeated-measures ANOVA was used to examine differences in biomarker levels between reference group and early-onset placental dysfunction, late-onset PE, PIH and over the multiple time points, to assess the effects of gestational age, and to determine if the course of biomarker levels over the multiple time points differs between placental dysfunction and reference group (i.e., whether an interaction between gestational age and group is present).

For the second aim, the longitudinal change was calculated as the second measurement divided by the value of a measurement at an earlier gestational age. This value was expressed as a longitudinal change (\%) compared with the earlier measurement. For example, to calculate the percentage of change in serum level compared to an earlier measurement of PlGF between 12 and 30 weeks: $\left((\mathrm{PlGF}\right.$ at 30 weeks/PlGF at 12 weeks $\left.\left.){ }^{\star} 100\right)\right)$.

The performance of detecting placental dysfunction by PlGF, sFlt- 1 and sFlt-1/PlGF ratio by single measurements at $12,16,20$ and 30 weeks, as well as the longitudinal change was determined by a univariate analysis of the (delta) biomarker with a binary logistic regression followed by a receiver operator characteristic (ROC) curve analysis. The area under the curves (AUCs) were used to assess the ability to discriminate between placental dysfunction and control group. IBM SPSS 23 (SPSS Inc. Chicago, IL, USA) was used for statistical analysis.

\section{Results}

\section{Different outcome groups}

Of a total of 207 singleton high-risk pregnancies, 133 had uncomplicated pregnancy outcomes (reference group) (64\%), 43 developed early-onset placental dysfunction (21\%), and 31 developed a late-onset placental dysfunction (15\%). The early-onset placental dysfunction group consisted of women with severe early-onset normotensive fetal growth restriction (n = 28), severe early-onset PE (before 34 weeks) (n $=9$ ), severe early-onset PE with fetal growth restriction $(\mathrm{n}=4)$ and placental abruption $(\mathrm{n}=2)$, no women developed eclampsia or HELLP syndrome. The late-onset placental dysfunction group consisted of 16 patients who developed late-onset PE (after 34 weeks) (7.7\%), none of them developed FGR, and 15 patients who developed pregnancy-induced hypertension (PIH, 7.2\%).

Maternal and fetal characteristics for each outcome group are summarized in Table 1. There were no 
significant differences between the groups in baseline characteristics, except in mean maternal height and autoimmune diseases. Early-onset placental dysfunction and late-onset PE groups had significant lower birthweight and a shorter gestational age at delivery compared with the reference group.

\section{PIGF, sFlt-1 and sFIt-1/PIGF ratio at 12, 16, 20 and 30 weeks of gestation}

Maternal serum levels of PlGF and sFlt-1 were determined in 757 samples from 207 patients. The maternal serum values of PlGF, sFlt-1 and sFLt-1/PlGF ratio were compared between each different outcome groups (early-onset placental dysfunction, late-onset PE, and $\mathrm{PIH}$ ) and the reference group at 12, 16, 20 or 30 weeks of gestation (Table 2). Mean maternal PlGF values were significantly lower in the early-onset placental dysfunction group compared to the reference group at 30 weeks $(256.6 \pm 142.30 \mathrm{pg} / \mathrm{ml}$ vs $400.2 \pm 224.55$, $\mathrm{p}=<0.001)$, but not at 12,16 and 20 weeks. No significant differences in PlGF values were found between the PIH group and late-onset PE group versus the reference group at any time point. Mean maternal sFlt-1 values were higher in the early-onset placental dysfunction, compared to the reference group, both at 20 weeks $(1454 \pm 1142.8 \mathrm{pg} / \mathrm{ml}$ vs $1139 \pm 579.8 \mathrm{pg} / \mathrm{ml}$, $\mathrm{p}=0.022)$, and at 30 weeks of gestation $(1993 \pm 1607.6$ $\mathrm{pg} / \mathrm{ml}$ vs $1459 \pm 881.7 \mathrm{pg} / \mathrm{ml}, \mathrm{p}=0.013)$. No significant differences in sFlt-1 values were found between the PIH group and late-onset $\mathrm{PE}$ group versus the reference group at any time point. Similarly, the sFlt-1/PlGF ratio was significantly higher in the early-onset placental dysfunction group compared to the reference group at 16 weeks $(30.6 \pm 58.30$ vs. $17.5 \pm 12.81, \mathrm{p}=0.012)$, at 20 weeks $(29.3 \pm 118.19$ vs $8.9 \pm 5.8, \mathrm{p}=0.036)$, and at 30 weeks $(16.6 \pm 29.90$ vs $6.7 \pm 14.77, \mathrm{p}=0.006)$.

The effect of time was different between the early-onset placental dysfunction, late-onset $\mathrm{PE}$ and PIH versus reference. The interaction effect of group * time was statistically significant in PlGF for early-onset placental dysfunction $(\mathrm{p}<0.001)$ and PIH ( $p=0.036)$ vs the reference group. The interaction effect was also significant in the sFlt-1/PlGF

Table 1. Baseline characteristics, reference group vs early-onset placental dysfunction (EO-PD), late-onset preeclampsia (LO-PE) and pregnancy-induced hypertension (PIH).

\begin{tabular}{|c|c|c|c|c|c|c|c|}
\hline Characteristics & $\begin{array}{l}\text { Reference group } \\
\quad(n=133)\end{array}$ & $\begin{array}{l}\text { EO-PD } \\
(n=43)\end{array}$ & $p$-Value & $\begin{array}{l}\text { LO-PE } \\
(n=16)\end{array}$ & $p$-Value & $\begin{array}{c}\mathrm{PIH} \\
(n=15)\end{array}$ & $p$-Value \\
\hline Maternal age (years) & $33.0(30.0-36.0)$ & $33.0(31.0-35.0)$ & 0.944 & $33.0(32.0-35.8)$ & 0.433 & $30.0(27.0-33.0)$ & 0.057 \\
\hline Pre-pregnancy BMI & $25.7( \pm 5.2)$ & $25.7( \pm 4.9)$ & 0.934 & $25.2( \pm 4.1)$ & 0.700 & $26.6( \pm 5.3)$ & 0.541 \\
\hline Pre-pregnancy weight (kg) & $72.8( \pm 15.4)$ & $69.6( \pm 14.7)$ & 0.229 & $70.2( \pm 14.2)$ & 0.516 & $71.1( \pm 11.5)$ & 0.701 \\
\hline Pre-pregnancy height $(\mathrm{cm})$ & $167.7( \pm 6.1)$ & $164.5( \pm 6.8)$ & $0.005^{*}$ & $166.3( \pm 5.8)$ & 0.411 & $166.6( \pm 6.6)$ & 0.531 \\
\hline Nulliparity $(n / N) \%$ & $17.3(23 / 133)$ & $23.3(10 / 43)$ & 0.377 & $31.3(5 / 16)$ & 0.177 & $40.0(6 / 15)$ & 0.078 \\
\hline \multicolumn{8}{|l|}{ Mode of conception $(\mathrm{n} / \mathrm{N}) \%$} \\
\hline Spontaneous & $95.5(127 / 133)$ & $97.7(42 / 43)$ & 0.524 & $81.3(13 / 16)$ & 0.057 & $86.7(13 / 15)$ & 0.188 \\
\hline Ovulation induction & $1.5(2 / 133)$ & $2.3(1 / 43)$ & 0.737 & $0(0 / 16)$ & 0.825 & $0(0 / 15)$ & 0.825 \\
\hline IUI & $1.5(2 / 133)$ & $0(0 / 43)$ & 0.568 & $6.3(1 / 16)$ & 0.268 & $0(0 / 15)$ & 0.825 \\
\hline IVF & $0.8(1 / 133)$ & $0(0 / 43)$ & 0.753 & $6.3(1 / 16)$ & 0.188 & $6.7(1 / 15)$ & 0.188 \\
\hline ICSI & $0.8(1 / 133)$ & $0(0 / 43)$ & 0.745 & $6.3(1 / 16)$ & 0.187 & $6.7(1 / 15)$ & 0.199 \\
\hline \multicolumn{8}{|l|}{ Ethnicity $(\mathrm{n} / \mathrm{N}) \%$} \\
\hline Caucasian & $94.0(125 / 133)$ & $95.3(41 / 43)$ & 0.700 & $100(16 / 16)$ & 0.643 & $80(12 / 15)$ & 0.083 \\
\hline Afro-Caribbean & $0.8(1 / 133)$ & $2.3(1 / 43)$ & 0.430 & $0(0 / 16)$ & 0.893 & $0(0 / 15)$ & 0.899 \\
\hline South Asian & $3.8(5 / 133)$ & $0(0 / 43)$ & 0.242 & $0(0 / 16)$ & 0.562 & $20.0(3 / 15)$ & $0.035^{*}$ \\
\hline East Asian & $0.8(1 / 133)$ & $0(0 / 43)$ & 0.756 & $0 .(0 / 16)$ & 0.893 & $0(0 / 15)$ & 0.899 \\
\hline Mixed/Other & $0.8(1 / 133)$ & $2.3(1 / 43)$ & 0.430 & $0 .(0 / 16)$ & 0.893 & $0 .(0 / 15)$ & 0.899 \\
\hline Cigarette smoker $(\mathrm{n} / \mathrm{N}) \%$ & $7.5(10 / 133)$ & $11.6(5 / 43)$ & 0.402 & $6.3(1 / 16)$ & 0.855 & $13.3(2 / 15)$ & 0.349 \\
\hline Chronic hypertension $(n / N) \%$ & $9.8(13 / 133)$ & $16.3(7 / 43)$ & 0.271 & $31.3(5 / 16)$ & $0.027^{*}$ & $0(0 / 15)$ & 0.363 \\
\hline Auto-immune disease $(\mathrm{n} / \mathrm{N}) \%$ & $15.0(20 / 133)$ & $23.3 \%(10 / 43)$ & 0.213 & $37.5(6 / 16)$ & $0.037^{*}$ & $6.7(1 / 15)$ & 0.378 \\
\hline Recurrent miscarriage(n/N) \% & $19.5(26 / 133)$ & $14.0(6 / 43)$ & 0.499 & $12.5(2 / 16)$ & 0.737 & $20.0(3 / 15)$ & 0.866 \\
\hline $\begin{array}{l}\text { PS in previous pregnancy }(\mathrm{n} / \mathrm{N}) \% \\
\text { Gender neonate }\end{array}$ & $66.9(89 / 133)$ & $67.4(29 / 43)$ & 0.949 & $50.0(8 / 16)$ & 0.266 & $53.3(8 / 15)$ & 0.390 \\
\hline Male \% (n) & $45.1(60 / 133)$ & $39.5(17 / 43)$ & 0.522 & $62.5(10 / 16)$ & 0.147 & $26.7(4 / 15)$ & 0.137 \\
\hline Gestational age at delivery (days) & $269(264-276)$ & $266(258-271)$ & $0.008^{*}$ & $262(259-263)$ & $<0.001^{*}$ & $271(266-276)$ & 0.736 \\
\hline Time between measurement (30wks) and delivery & $59( \pm 9.2)$ & $50( \pm 21.5)$ & $<.001^{*}$ & $49( \pm 7.1)$ & $0.014^{*}$ & $60( \pm 7.0)$ & 0.815 \\
\hline Birthweight in gram & $3291( \pm 440)$ & $2344( \pm 584)$ & $<.001^{*}$ & $2964( \pm 242)$ & $0.007^{*}$ & $3354( \pm 331)$ & 0.613 \\
\hline $\begin{array}{l}\text { Birthweight percentile in \% } \\
\text { Medication }(\mathrm{n} / \mathrm{N}) \%\end{array}$ & $53.7(26.4-76.6)$ & $5.9(1.7-7.7)$ & $<.001^{*}$ & $52.9(37.8-65.0)$ & 0.902 & $60.9(28.9-77.5)$ & 0.643 \\
\hline Aspirin & $88.0(117 / 133)$ & $79.1(34 / 43)$ & 0.129 & $81.3(13 / 16)$ & 0.415 & $80.0(12 / 15)$ & 0.398 \\
\hline Antihypertensive treatment & $80.5(107 / 133)$ & $90.7(39 / 43)$ & 0.162 & $75.0(12 / 16)$ & 0.967 & $93.3(14 / 15)$ & 0.307 \\
\hline
\end{tabular}

Legend: Categorical data are presented as percentage $(\mathrm{n} / \mathrm{N})$. Continuous data are presented as mean \pm standard deviation. $p$-Values given for each outcome group compared with the reference group. Early-onset placental dysfunction (EO-PD): preeclampsia (PE), fetal growth restriction, Hemolysis Elevated Liver enzymes and Low Platelets (HELLP) and placental abruption developed before 34 weeks. Late-onset pre-eclampsia (LO-PE), preeclampsia developed after 34 weeks of gestation; PIH, pregnancy-induced hypertension; IUI, intrauterine insemination; IVF, in-vitro fertilization; ICSI, Intracytoplasmic sperm injection. ${ }^{*} p$-Value $<0.05$. 
Table 2. Biomarkers, reference group vs early-onset placental dysfunction (EO-PD), late-onset preeclampsia (LO-PE) and pregnancyinduced hypertension (PIH) PIGF, sFlt-1 and the ratio at 12, 16, 20, and 30 weeks.

\begin{tabular}{|c|c|c|c|c|c|c|c|}
\hline PIGF (pg/mL) & 12 weeks & 16 weeks & 20 weeks & 30 weeks & Group & Time & Group $\times$ Time \\
\hline Reference & $30.1 \pm 11.09$ & $76.5 \pm 91.91$ & $149.4 \pm 69.83$ & $400.2 \pm 224.55$ & $<0.001^{*}$ & $<0.001^{*}$ & $<0.001^{*}$ \\
\hline EO-PD & $33.3 \pm 17.87$ & $74.4 \pm 34.22$ & $140.0 \pm 76.21$ & $256.6 \pm 142.30$ & & & \\
\hline$p$-Value & 0.229 & 0.738 & 0.459 & $<0.001^{*}$ & & & \\
\hline $\begin{array}{l}\text { LO-PE } \\
p \text {-Value }\end{array}$ & $\begin{array}{c}31.7 \pm 14.77 \\
0.684\end{array}$ & $\begin{array}{c}87.7 \pm 37.59 \\
0.216\end{array}$ & $\begin{array}{c}167.5 \pm 71.11 \\
0.372\end{array}$ & $\begin{array}{c}413.7 \pm 286.64 \\
0.827\end{array}$ & 0.514 & $<0.001^{*}$ & 0.989 \\
\hline $\begin{array}{l}\text { PIH } \\
p \text {-Value }\end{array}$ & $\begin{array}{c}32.1 \pm 14.55 \\
0.626\end{array}$ & $\begin{array}{c}78.8 \pm 34.72 \\
0.805\end{array}$ & $\begin{array}{c}161.0 \pm 78.81 \\
0.553\end{array}$ & $\begin{array}{c}439.3 \pm 265.01 \\
0.516\end{array}$ & 0.129 & $<0.001^{*}$ & $0.036^{*}$ \\
\hline \multicolumn{8}{|l|}{ sFlt-1 (pg/mL) } \\
\hline Reference & $1128 \pm 482.6$ & $1158 \pm 571.7$ & $1139 \pm 579.8$ & $1459 \pm 881.7$ & $<0.001^{*}$ & $<0.001^{*}$ & 0.088 \\
\hline EO PD & $1195 \pm 503.2$ & $1270 \pm 614.4$ & $1454 \pm 1142.8$ & $1993 \pm 1607.6$ & & & \\
\hline$p$-Value & 0.494 & 0.309 & $0.022^{*}$ & $0.013^{*}$ & & & \\
\hline LO-PE & $1362 \pm 564.4$ & $1322 \pm 552.8$ & $1315 \pm 824.6$ & $1896 \pm 1233.1$ & $0.007^{*}$ & $0.001 *$ & 0.712 \\
\hline$p$-Value & 0.100 & 0.320 & 0.420 & 0.176 & & & \\
\hline $\mathrm{PIH}$ & $1207 \pm 587.2$ & $1242 \pm 845.1$ & $1300 \pm 898.2$ & $1626 \pm 1465.1$ & 0.569 & $0.013^{*}$ & 0.989 \\
\hline$p$-Value & 0.601 & 0.620 & 0.444 & 0.593 & & & \\
\hline \multicolumn{8}{|l|}{ sFIt-1/PIGF } \\
\hline Reference & $41.7 \pm 23.75$ & $17.5 \pm 12.81$ & $8.9 \pm 5.81$ & $6.7 \pm 14.77$ & $0.001^{*}$ & $<0.001^{*}$ & $0.004^{*}$ \\
\hline EO PD & $46.9 \pm 35.14$ & $30.6 \pm 58.30$ & $29.3 \pm 118.19$ & $16.6 \pm 29.90$ & & & \\
\hline$p$-Value & 0.309 & $0.012^{*}$ & $0.036^{*}$ & $0.006^{*}$ & & & \\
\hline LO-PE & $49.4 \pm 25.06$ & $19.1 \pm 15.55$ & $9.0 \pm 5.98$ & $9.7 \pm 10.90$ & 0.146 & $<0.001 *$ & 0.627 \\
\hline$p$-Value & 0.295 & 0.833 & 0.994 & 0.579 & & & \\
\hline PIH & $40.3 \pm 17.14$ & $18.3 \pm 14.45$ & $9.9 \pm 9.04$ & $20.5 \pm 19.31$ & 0.297 & $<0.001^{*}$ & 0.957 \\
\hline$p$-Value & 0.866 & 0.918 & 0.948 & 0.672 & & & \\
\hline
\end{tabular}

Continuous data are presented as mean \pm standard deviation. $p$-Values given for each outcome group compared with the reference group. Early-onset placental dysfunction (EO-PD): preeclampsia (PE), fetal growth restriction, Hemolysis Elevated Liver enzymes and Low Platelets (HELLP) and placental abruption developed before 34 weeks late-onset pre-eclampsia (LO-PE), preeclampsia developed after 34 weeks of gestation; PIH, pregnancy-induced hypertension; Repeated measures ANOVA: Group: EO-PD, LO-PE or PIH vs reference group. Time: 12, 16, 20, and 30 weeks of gestational age. Group $\times$ time: interaction between groups and gestational age. ${ }^{*} p$-value $<0.05$.

PIGF, placental growth factor. sFlt-1, soluble fms-like tyrosine kinase 1.

ratio for early-onset placental dysfunction $(\mathrm{p}=$ 0.004) vs reference group.

\section{Longitudinal changes in PIGF, sFlt-1 and sFIt-1/PIGF ratio}

The longitudinal changes between PlGF, sFlt-1 and the ratio among the four different outcome groups are displayed in Table 3. Patients who developed early-onset placental dysfunction, compared to the reference group, had a lower increase in PlGF (\%) at $12-30(\mathrm{p}=0.003), 16-30(\mathrm{p}=0.002)$, and $20-30$ week interval $(\mathrm{p}<0.001)$, and a higher increase in sFlt-1 $(\%)$ at $12-20(\mathrm{p}=0.011), 12-30$ weeks; $(\mathrm{p}=$ $0.049), 16-20(\mathrm{p}=0.030)$ and at $16-30$ weeks $(\mathrm{p}=$ 0.020 ). Similarly, the sFlt-1/PlGF ratio showed less decrease in the EO-PD group vs reference group at $12-20(\mathrm{p}=0.011), 12-30(\mathrm{p}=0.032), 16-30(\mathrm{p}=$ $0.008)$ and the 20-30 weeks interval $(\mathrm{p}=0.004)$.

No significant differences in longitudinal values of biomarkers were detected for the late-onset $\mathrm{PE}$ or the $\mathrm{PIH}$ vs reference group at any time interval.

\section{PIGF, sFIt-1 and sFIt-1/PIGF ratio in predicting early-onset placental dysfunction}

The sFlt-1/PlGF ratio had a better performance for the prediction of early-onset placental dysfunction (Table 4) than either sFlt-1 or PlGF alone (data not shown). For single time point measurements, the diagnostic differentiation (AUC) increased with gestational age from $0.51(0.19-0.62)$ at 12 weeks to $0.7(0.60-0.78)$ at 30 weeks. The longitudinal change of sFlt-1/PlGF ratio for all intervals starting from 12, 16 or 20 weeks had higher AUC than single measurements at 12,16 or 20 weeks, respectively. No difference in AUC was seen between the single measurement at 30 weeks and the longitudinal change for all intervals ending with 30 weeks (all around $0.7)$.

\section{Discussion}

\section{Interpretation of main findings}

This study demonstrated that at 30 weeks of gestation PlGF and sFlt- 1 are both significantly different among patients who developed early-onset placental dysfunction when compared to the reference group. Earlier in pregnancy, at 16 weeks, the sFlt-1/PlGF ratio was already significantly higher in the early-onset placental dysfunction versus the reference group. In the early-onset placental dysfunction group, PlGF had a significantly lower increase during gestation and sFlt-1 has a significantly higher increase when compared to the reference group. This is in agreement with previous studies who found that a lower increase in maternal serum PlGF is a risk factor for the subsequent 
Table 3. Longitudinal change of PIGF, sFlt-1 and the sFlt-1/PIGF ratio.

\begin{tabular}{|c|c|c|c|c|c|c|c|}
\hline PIGF $(p g / m L)$ & Reference & EO-PD & $p$-value & LO-PE & $p$-value & $\mathrm{PIH}$ & $p$-value \\
\hline $12-16$ & $161 \% \pm 99.3$ & $142 \% \pm 102.2$ & 0.320 & $180 \% \pm 74.3$ & 0.491 & $142 \% \pm 61.8$ & 0.508 \\
\hline $12-20$ & $423 \% \pm 224.6$ & $386 \% \pm 388.4$ & 0.461 & $485 \% \pm 126.7$ & 0.414 & $357 \% \pm 135.7$ & 0.400 \\
\hline $12-30$ & $1268 \% \pm 718.7$ & $828 \% \pm 629.8$ & $0.003^{*}$ & $1128 \% \pm 675.1$ & 0.517 & $1329 \% \pm 803.2$ & 0.779 \\
\hline $16-20$ & $104 \% \pm 64.1$ & $101 \% \pm 72.1$ & 0.780 & $115 \% \pm 49.6$ & 0.581 & $99 \% \pm 42.0$ & 0.758 \\
\hline $16-30$ & $441 \% \pm 299.8$ & $276 \% \pm 214.3$ & $0.002^{*}$ & $214 \% \pm 219.8$ & 0.138 & $472 \% \pm 227.5$ & 0.692 \\
\hline $20-30$ & $169 \% \pm 120.5$ & $85 \% \pm 80.9$ & $<0.001^{*}$ & $136 \% \pm 142.1$ & 0.344 & $183 \% \pm 119.3$ & 0.667 \\
\hline \multicolumn{8}{|l|}{ sFIt-1 (pg/mL) } \\
\hline $12-16$ & $2 \% \pm 29.8$ & $12 \% \pm 31.8$ & 0.132 & $-1 \% \pm 39.1$ & 0.720 & $5 \% \pm 30.2$ & 0.769 \\
\hline $12-20$ & $2 \% \pm 37.6$ & $31 \% \pm 89.7$ & $0.011^{*}$ & $8 \% \pm 88.2$ & 0.730 & $9 \% \pm 43.0$ & 0.714 \\
\hline $12-30$ & $39 \% \pm 77.4$ & $83 \% \pm 167.8$ & $0.049^{*}$ & $59 \% \pm 155.7$ & 0.530 & $42 \% \pm 72.6$ & 0.928 \\
\hline $16-20$ & $0.4 \% \pm 20.6$ & $10 \% \pm 31.7$ & $0.030^{*}$ & $-0.3 \% \pm 28.0$ & 0.915 & $5 \% \pm 17.5$ & 0.475 \\
\hline $16-30$ & $35 \% \pm 62.5$ & $65 \% \pm 88.6$ & $0.020^{*}$ & $39 \% \pm 67.9$ & 0.821 & $32 \% \pm 42.5$ & 0.880 \\
\hline $20-30$ & $38 \% \pm 92.1$ & $67 \% \pm 119.6$ & 0.100 & $35 \% \pm 44.3$ & 0.920 & $23 \% \pm 41.1$ & 0.567 \\
\hline \multicolumn{8}{|l|}{ sFIt-1/PIGF } \\
\hline $12-16$ & $-56 \% \pm 22.4$ & $-46 \% \pm 33.2$ & 0.062 & $-63 \% \pm 13.8$ & 0.258 & $-53 \% \pm 19.7$ & 0.753 \\
\hline $12-20$ & $-77 \% \pm 15.4$ & $-58 \% \pm 76.5$ & $0.011^{*}$ & $-81 \% \pm 13.7$ & 0.715 & $-74 \% \pm 14.5$ & 0.755 \\
\hline $12-30$ & $-83 \% \pm 30.8$ & $-69 \% \pm 79.9$ & $0.032^{*}$ & $-82 \% \pm 15.5$ & 0.955 & $-81 \% \pm 30.8$ & 0.911 \\
\hline $16-20$ & $-46 \% \pm 22.0$ & $-39 \% \pm 30.3$ & 0.111 & $-51 \% \pm 18.8$ & 0.510 & $-45 \% \pm 13.2$ & 0.891 \\
\hline $16-30$ & $-62 \% \pm 60.6$ & $-27 \% \pm 100.4$ & $0.008^{*}$ & $-53 \% \pm 34.4$ & 0.680 & $-69 \% \pm 31.9$ & 0.722 \\
\hline $20-30$ & $-25 \% \pm 113.0$ & $59 \% \pm 271.0$ & $0.004^{*}$ & $-7 \% \pm 74.4$ & 0.704 & $-40 \% \pm 50.2$ & 0.735 \\
\hline
\end{tabular}

Longitudinal change is presented as percentage (\%) \pm standard deviation. $p$-Values given for each outcome group compared with the reference group. Earlyonset placental dysfunction (EO-PD): developed before 34 weeks. Late-onset pre-eclampsia (LO-PE), preeclampsia; PIH, pregnancy-induced hypertension; ${ }^{*} p$-value $<0.05$.

PIGF, placental growth factor. sFlt-1, soluble fms-like tyrosine kinase 1.

development of placental dysfunction $(27,34,40)$. The difference between PlGF in the early-onset placental dysfunction and the reference group increases with gestation, which is also consistent with earlier studies $(27,28,32$ $34,40)$. The interaction effect of group and time was tested and showed that both have a significant influence on the PlGF and sFlt-1/PlGF values for early-onset placental dysfunction during pregnancy.

These study results also confirm that not only earlyonset PE but also FGR and placental abruption are related to an imbalance in sFlt-1 and PlGF (41). Both early-onset placental dysfunction disorders may have the same underlying pathology from inadequate trophoblastic invasion, that leads to insufficient remodeling of the spiral arteries, resulting in placental under perfusion and ischemia. This causes short-time maternal and fetal consequences, and at a longer period of time possibly a higher risk on cardiovascular disease (37).

Furthermore, this study demonstrated that patients who developed late-onset PE after 34 weeks of gestation did not show any significant differences in PlGF and sFlt-1, when compared to the reference group. It reflects a heterogeneous condition with minimal placental involvement. This is in line with our earlier hypothesis that late-onset placental dysfunction is thought to be associated with trophoblast dysfunction due to villous overcrowding in term placentas, leading to diminished intervillous perfusion and increased hypoxia. Later in pregnancy, especially at term, the increased placenta demands more than the uterine vasculature is able to provide (25).
Table 4. Performance of screening for early-onset placental dysfunction in high-risk population by the sFlt-1/PIGF ratio.

\begin{tabular}{lcc}
\hline $\begin{array}{l}\text { Screening measurement } \\
\text { sFlt-1/PIGF ratio for placental } \\
\text { dysfunction }\end{array}$ & AUC $(95 \%$ Cl) & $\begin{array}{c}\text { Odds ratio logistic } \\
\text { regression }\end{array}$ \\
\hline 12 weeks & $0.51(0.19-0.62)$ & $1.006(0.993-1.019)$ \\
16 weeks & $0.55(0.44-0.65)$ & $1.016(0.998-1.035)$ \\
20 weeks & $0.61(0.52-0.71)$ & $1.050(1.001-1.101)$ \\
30 weeks & $0.69(0.60-0.78)$ & $1.020(1.003-1.038)$ \\
Relative change 12-16 & $0.63(0.53-0.73)$ & $3.875(0.93316 .085)$ \\
Relative change 12-20 & $0.71(0.62-0.80)$ & $10.002(0.930-107.631)$ \\
Relative change 12-30 & $0.70(0.61-0.80)$ & $2.213(0.884-5.542)$ \\
Relative change 16-20 & $0.60(0.50-0.70)$ & $3.144(0.788-12.548)$ \\
Relative change 16-30 & $0.70(0.61-0.79)$ & $1.771(1.083-2.897)$ \\
Relative change 20-30 & $0.69(0.60-0.78)$ & $1.344(1.040-1.737)$ \\
\hline
\end{tabular}

Data are given as area under the curve (AUC) with $95 \%$ confidence interval (CI). ROC, receiver operating characteristics. PIGF, placental growth factor. sFlt-1, soluble fms-like tyrosine kinase 1.

\section{Longitudinal change}

The second objective was to assess whether the performance of screening by these biomarkers is improved by calculating the longitudinal biomarker changes instead of single timepoint biomarker measurements. Several studies investigating the longitudinal changes in maternal serum sFlt-1 and PlGF levels found that longitudinal measurements form better predictors than measurements at a single point during pregnancy $(28,32,34)$. This study confirmed that a single measurement of sFlt-1 and PlGF in the first or early second trimester are poor predictors of developing early-onset placental dysfunction; however, the overall performance could be improved by repeated measurements $(28,32)$. Women with early-onset placental dysfunction, compared to the reference group, had a lower increase 
in PlGF and a higher increase in sFlt- 1 at $12-30,16-30$ and $20-30$ weeks. Similarly, the sFlt-1/PlGF ratio showed less decrease in the early-onset placental dysfunction group vs reference group at 12-20, 12-30, 16-30 and the 20-30 week interval. These differences in longitudinal values were not seen in the late-onset placental dysfunction group, confirming the different underlying pathology.

The sFlt-1/PlGF ratio had a better performance for the prediction of early-onset placental dysfunction than either sFlt-1 or PlGF alone. For single time point measurements, the diagnostic differentiation (AUC) increased with gestational age from $0.51(0.19-0.62)$ at 12 weeks to $0.7(0.60-0.78)$ at 30 weeks. The longitudinal change of sFlt-1/PlGF ratio for all intervals starting from 12, 16 or 20 weeks had higher AUC than single measurements at 12,16 or 20 weeks, respectively.

Our results show that the interval between the last blood sampling (all around 30 weeks) and delivery was different between the groups, but it is merely a reflection of the difference in gestational age at delivery. Hence, we argue that the measurement-delivery time interval has little influence on the biomarker values in this study.

There is no consensus on the ideal time point in pregnancy to perform biochemical screening for late placental dysfunction. Measurement at 36 weeks would have a better performance for the prediction of late preeclampsia, necessitating delivery after 37 weeks, compared with 30 weeks (42). Screening for late FGR using the same panel of biomarkers was feasible at 36 weeks of gestation but performed worse than screening for late preeclampsia (43). It is possible that late-onset preeclampsia has a milder placental dysfunction at 30 weeks, which leads to smaller changes in biomarker levels. However, a more tempting theory is that lateonset preeclampsia has a different pathophysiology to early-onset disease, and that this is reflected on the maternal serum biomarker profile. We speculate that, as the vascular entity leading to late-onset preeclampsia worsens toward the end of pregnancy, a disbalance in biomarker ratio occurs which resembles that of earlyonset preeclampsia, albeit different in its source, severity and rate of development. This is supported by that fact that in both early- and late-onset subtypes, the closer the measurement is to the clinical presentation (or the indicated delivery), the more deranged the biomarker is (44).

\section{High-risk population}

A high-risk population was selected to screen for different placental dysfunction profiles. The incidence of placental dysfunction in this study population is $20.8 \%$.
Also, because patients were included in this high-risk monitoring program, as described earlier, the gestational age between the patients at 12, 16, 20 and 30 weeks were similar and found to be not significantly different. Hence, no additional measures were needed in order to "normalize" the data. Many studies have focused on low-risk populations, but only a few have evaluated the use of sFlt-1 and PlGF in a high-risk population $(33,40,45,46)$. In this study, we observed that PlGF was lower and sFlt-1 and sFlt-1/PlGF rate were higher in patients who develop placental dysfunction in comparison to the reference group. These findings, although not significant, are similar to that previously reported among low-risk patients $(27,28,30,32-36,45-48)$. This suggests that the pathogenesis of placental dysfunction in both low and highrisk women is similar.

The majority of the studied population used aspirin. It is hypothesized that aspirin improves the trophoblast cell integration by inhibiting the effects of Tumor Necrosis Factor alpha (TNFa); however, the effect of aspirin on the concentration of the (anti)angiogenic biomarkers is still unclear. Several studies have shown no significant effect on the concentration of PlGF and sFlt-1 with the use of aspirin $(40,49,50)$. However, an in-vitro study showed that the treatment of aspirin in patients with PE increased the PlGF concentrations (51). The improvement in serum PlGF concentrations by aspirin might explain the small difference between 12 and 20 weeks in PlGF in this study. There is no conclusive data on the effect of methyldopa and labetalol on sFlt-1 and PlGF (52,53).

\section{Strengths and limitations}

One of the strengths of this study is that it looked at different phenotypes of placental dysfunction, whereas most studies have only focused on PE. Even though multiple obstetric syndromes have been proven to be associated with poor placentation and both PE and FGR have previously shown to be associated with an imbalance in pro-angiogenic and anti-angiogenic factors $(27,28,41,54)$. Another strength of this study is that it examined the changes of these biomarkers during different pregnancy trimesters. One of the limitations of this study is its retrospective cohort design with substantial loss to follow-up, which makes this study susceptible to bias. Another limitation of this study is the small study sample, with a small range in ethnic profile and mode of conception-decreasing generalizability. 


\section{Conclusion}

This study confirms that in a high-risk population, early and late-onset placental dysfunction differ in their angiogenic profile, suggesting a different underlying mechanism. In the third trimester all individual biomarkers were significantly related to early-onset placental dysfunction, while in the second trimester only the sFlt-1/PlGF ratio values were different. However, the longitudinal change of the sFlt-1/PlGF ratio is already discriminatory from the first trimester.

In order to further investigate the use of the longitudinal change to improve the performance of screening, a large prospective longitudinal study design is required to assess the likelihood of early placental dysfunction based on longitudinal change of sFlt-1, PlGF and the ratio.

\section{Key message}

In high-risk women, differences in angiogenic biomarkers PlGF, sFlt-1 and more importantly sFlt-1/PlGF ratio were found in early-onset placental dysfunction, but not in late-onset placental dysfunction. Longitudinal change in these biomarkers between 12 and 30 weeks marginally improved the prediction of early-onset placental dysfunction compared to measurement at a single time point.

\section{Data availability statement}

The dataset used and analyzed during the current study is available from the corresponding author, manouk.hendrix@mumc.nl, upon reasonable request.

\section{Disclosure statement}

No potential conflict of interest was reported by the authors.

\section{ORCID}

Manouk L. E. Hendrix (1) http://orcid.org/0000-0002-99545822

\section{References}

[1] Brosens I, Pijnenborg R, Vercruysse L, et al. The "Great Obstetrical Syndromes" are associated with disorders of deep placentation. Am J Obstet Gynecol. 2011;204(3):193-201.

[2] Khong Y, Brosens I. Defective deep placentation. Best Pract Res Clin Obstet Gynaecol. 2011;25(3):301-311.

[3] Romero R, Kusanovic JP, Chaiworapongsa T, et al. Placental bed disorders in preterm labor, preterm PROM, spontaneous abortion and abruptio placentae.
Best Pract Res Clin Obstet Gynaecol. 2011;25 (3):313-327.

[4] Brosens I. Placental bed \& maternal - fetal disorders Preface. Best Pract Res Clin Obstet Gynaecol. 2011;25 (3):247-248.

[5] Frusca T, Morassi L, Pecorelli S, et al. Histological features of uteroplacental vessels in normal and hypertensive patients in relation to birthweight. Br J Obstet Gynaecol. 1989;96(7):835-839.

[6] Hustin J, Foidart JM, Lambotte R. Maternal vascular lesions in pre-eclampsia and intrauterine growth retardation: light microscopy and immunofluorescence. Placenta. 1983;4:489-498.

[7] Cantwell R, Clutton-Brock T, Cooper G, et al. Saving Mothers' Lives: reviewing maternal deaths to make motherhood safer: 2006-2008. The Eighth Report of the Confidential Enquiries into Maternal Deaths in the United Kingdom. BJOG. 2011;118(Suppl 1):1-203.

[8] Say L, Chou D, Gemmill A, et al. Global causes of maternal death: a WHO systematic analysis. Lancet Glob Health. 2014;2(6):e323-33.

[9] Bujold E, Roberge S, Lacasse Y, et al. Prevention of preeclampsia and intrauterine growth restriction with aspirin started in early pregnancy: a meta-analysis. Obstet Gynecol. 2010;116(2 Pt 1):402-414.

[10] Villa PM, Marttinen P, Gillberg J, et al. Cluster analysis to estimate the risk of preeclampsia in the high-risk Prediction and Prevention of Preeclampsia and Intrauterine Growth Restriction (PREDO) study. PLoS One. 2017;12(3):e0174399.

[11] Frampton GK, Jones J, Rose M, et al. Placental growth factor (alone or in combination with soluble fms-like tyrosine kinase 1) as an aid to the assessment of women with suspected pre-eclampsia: systematic review and economic analysis. Health Technol Assess. 2016;20(87):1-160.

[12] Groom KM, David AL. The role of aspirin, heparin, and other interventions in the prevention and treatment of fetal growth restriction. Am J Obstet Gynecol. 2018;218(2S):S829-S40.

[13] Shibuya M. Vascular Endothelial Growth Factor (VEGF) and Its Receptor (VEGFR) Signaling in Angiogenesis: A Crucial Target for Anti- and Pro-Angiogenic Therapies. Genes Cancer. 2011;2 (12):1097-1105.

[14] Chau K, Hennessy A, Makris A. Placental growth factor and pre-eclampsia. J Hum Hypertens. 2017;31 (12):782-786.

[15] Vrachnis N, Kalampokas E, Sifakis S, et al. Placental growth factor (PlGF): A key to optimizing fetal growth. J Matern Fetal Neonatal Med. 2013;26(10):995-1002.

[16] Weissgerber T, Rajakumar A, Myerski AC, et al. Vascular pool of releasable soluble VEGF receptor-1 (sFLT1) in women with previous preeclampsia and uncomplicated pregnancy. J Clin Endocrinol Metab. 2014 Mar;99(3):978-987. . Epub 2013 Dec 11.

[17] Maynard SE, Min J-Y, Merchan J, et al. Excess placental soluble fms-like tyrosine kinase 1 (sFlt1) may contribute to endothelial dysfunction, hypertension, and proteinuria in preeclampsia. J Clin Invest. 2003 Mar;111(5):649-658. 
[18] Herzog EM, Eggink AH, Reijnierse A, et al. Impact of early- and late-onset preeclampsia on features of placental and newborn vascular health. Placenta. 2017;49:72-79.

[19] Redman CW, Staff AC. Preeclampsia, biomarkers, syncytiotrophoblast stress, and placental capacity. Am J Obstet Gynecol. 2015;213(4Suppl):S9e1, S9-11.

[20] Pinheiro CC, Rayol P, Gozzani L, et al. The relationship of angiogenic factors to maternal and neonatal manifestations of early-onset and late-onset preeclampsia. Prenat Diagn. 2014;34(11):1084-1092.

[21] Zhang X, Jia H, Wang Y, et al. Early and late onset severe preeclampsia: a clinicopathologic study of 178 placentas. Zhonghua Bing Li Xue Za Zhi. 2015;44(12):879-883.

[22] Redman WC. Early and late onset preeclampsia: two sides of the same coin. Pregnancy Hypertens. 2017 Jan;7.

[23] Thilaganathan B. Association of Higher Maternal Blood Pressure With Lower Infant Birthweight: placental Cause or Cardiovascular Effect?. Hypertension. 2016;67(3):499-500.

[24] Kalafat E, Thilaganathan B. Cardiovascular origins of preeclampsia. Curr Opin Obstet Gynecol. 2017 Dec;29 (6):383-389.

[25] Ness RB, Roberts JM. Heterogeneous causes constituting the single syndrome of preeclampsia: a hypothesis and its implications. Am J Obstet Gynecol. 1996 Nov;175(5):1365-1370.

[26] Brandao AH, Felix LR, Patricio Edo C, et al. Difference of endothelial function during pregnancies as a method to predict preeclampsia. Arch Gynecol Obstet. 2014;290:471-477.

[27] Erez O, Romero R, Espinoza J, et al. The change in concentrations of angiogenic and anti-angiogenic factors in maternal plasma between the first and second trimesters in risk assessment for the subsequent development of preeclampsia and small-for-gestational age. J Matern Fetal Neonatal Med. 2008;21(5):279-287.

[28] Romero R, Nien JK, Espinoza J, et al. A longitudinal study of angiogenic (placental growth factor) and anti-angiogenic (soluble endoglin and soluble vascular endothelial growth factor receptor-1) factors in normal pregnancy and patients destined to develop preeclampsia and deliver a small for gestational age neonate. J Matern Fetal Neonatal Med. 2008;21 (1):9-23.

[29] Chaiworapongsa T, Romero R, Espinoza J, et al. Evidence supporting a role for blockade of the vascular endothelial growth factor system in the pathophysiology of preeclampsia. Young Investigator Award. Am J Obstet Gynecol. 2004;190(6):1541-7; discussion 7-50.

[30] Levine RJ, Lam C, Qian C, et al. Soluble endoglin and other circulating antiangiogenic factors in preeclampsia. N Engl J Med. 2006;355(10):992-1005.

[31] Jaaskelainen T, Heinonen S, Hamalainen E, et al. Angiogenic profile in the Finnish Genetics of Pre-Eclampsia Consortium (FINNPEC) cohort. Pregnancy Hypertens. 2018;14:252-259.

[32] Andrietti S, Carlucci S, Wright A, et al. Repeat measurements of uterine artery pulsatility index, mean arterial pressure and serum placental growth factor at 12, 22 and 32 weeks in prediction of pre-eclampsia. Ultrasound Obstet Gynecol. 2017;50(2):221-227.
[33] Khalil A, Maiz N, Garcia-Mandujano R, et al. Longitudinal changes in maternal serum placental growth factor and soluble fms-like tyrosine kinase-1 in women at increased risk of pre-eclampsia. Ultrasound Obstet Gynecol. 2016;47(3):324-331.

[34] Rana S, Karumanchi SA, Levine RJ, et al. Sequential changes in antiangiogenic factors in early pregnancy and risk of developing preeclampsia. Hypertension. 2007;50(1):137-142.

[35] Myatt L, Clifton RG, Roberts JM, et al. Can changes in angiogenic biomarkers between the first and second trimesters of pregnancy predict development of pre-eclampsia in a low-risk nulliparous patient population?. BJOG. 2013;120(10):1183-1191.

[36] Perni U, Sison C, Sharma V, et al. Angiogenic factors in superimposed preeclampsia: a longitudinal study of women with chronic hypertension during pregnancy. Hypertension. 2012;59(3):740-746.

[37] Davis EF, Lazdam M, Lewandiwski AJ, et al. Cardiovascular risk factors in children and young adults born to preeclamptic pregnancies: a systematic review. Pediatrics. 2012;129:e1552-e1561.

[38] Brown MA, Lindheimer MD, de Swiet M, et al. The classification and diagnosis of the hypertensive disorders of pregnancy: statement from the International Society for the Study of Hypertension in Pregnancy (ISSHP). Hypertens Pregnancy. 2001;20(1):IX-XIV.

[39] Rad S, Beauchamp S, Morales C, et al. Defining fetal growth restriction: abdominal circumference as an alternative criterion. J Matern Fetal Neonatal Med. 2018;31(23:3089-3094.

[40] Powers RW, Jeyabalan A, Clifton RG, et al. Soluble fms-Like tyrosine kinase 1 (sFlt1), endoglin and placental growth factor (PlGF) in preeclampsia among high risk pregnancies. PLoS One. 2010;5(10):e13263.

[41] Ghosh SK, Raheja S, Tuli A, et al. Can maternal serum placental growth factor estimation in early second trimester predict the occurrence of early onset preclampsia and/or early onset intrauterine growth restriction? A prospective cohort study. J Obstet Gynaecol Res. 2013 May;39(5):881-890.

[42] Tsiakkis A. Maternal serum placental growth factor at 12, 22, 32 and 36 weeks' gestation in screening for preeclampsia. Ultrasound Obstet Gynecol. 2016 Apr;47(4):472-477.

[43] MacDonald TM. Assessing the sensitivity of placental growth factor and soluble fms-like tyrosine kinase 1 at 36 weeks' gestation to predict small-for-gestational-age infants or late-onset preeclampsia: a prospective nested case-control study. BMC Pregnancy Childbirth. 2018 Aug 31;18(1):354.

[44] Levine RJ, Maynard SE, Qian C, et al. Circulating angiogenic factors and the risk of preeclampsia. N Engl J Med. 2004;350:672-683.

[45] Agrawal S, Cerdeira AS, Redman C, et al. Meta-Analysis and Systematic Review to Assess the Role of Soluble FMS-Like Tyrosine Kinase-1 and Placenta Growth Factor Ratio in Prediction of Preeclampsia: the SaPPPhirE Study. Hypertension. 2018;71(2):306-316.

[46] Dover N, Gulerman HC, Celen S, et al. Placental growth factor: as an early second trimester predictive marker for preeclampsia in normal and high-risk 
pregnancies in a Turkish population. J Obstet Gynaecol India. 2013;63(3):158-163.

[47] Kleinrouweler CE, Wiegerinck MM, Ris-Stalpers C, et al. Accuracy of circulating placental growth factor, vascular endothelial growth factor, soluble fms-like tyrosine kinase 1 and soluble endoglin in the prediction of pre-eclampsia: a systematic review and meta-analysis. BJOG. 2012;119(7):778-787.

[48] Zeisler H, Llurba E, Chantraine F, et al. Predictive Value of the sFlt-1: plGFRatio in Women with Suspected Preeclampsia. N Engl J Med. 2016;374(1):13-22.

[49] Navaratnam K, Abreu P, Clarke H, et al. Evaluation of agreement of placental growth factor (PlGF) tests and the soluble FMS-like tyrosine kinase 1 (sFlt-1)/PlGF ratio, comparison of predictive accuracy for pre-eclampsia, and relation to uterine artery Doppler and response to aspirin. J Matern Fetal Neonatal Med. 2019;23(2):179-187.

[50] Xu B, Shanmugalingam R, Chau K, et al. The effect of acetyl salicylic acid (Aspirin) on trophoblast-endothelial interaction in vitro. J Reprod Immunol. 2017;124:54-61.
[51] Panagodage S, Yong HE, Da Silva Costa F, et al Low-Dose Acetylsalicylic Acid Treatment Modulates the Production of Cytokines and Improves Trophoblast Function in an in Vitro Model of Early-Onset Preeclampsia. Am J Pathol. 2016;186 (12):3217-3224.

[52] Khalil A, Muttukrishna S, Harrington K, et al. Effect of antihypertensive therapy with alpha methyldopa on levels of angiogenic factors in pregnancies with hypertensive disorders. PLoS One. 2008;3(7):e2766.

[53] Xu B, Thornton C, Tooher J, et al. Effects of anti-hypertensive drugs on production of soluble fms-like tyrosine kinase 1 and soluble endoglin from human normal and pre-eclamptic placentas in vitro. Clin Exp Pharmacol Physiol. 2009;36 (8):839-842.

[54] Stepan H, Faber R, Dornhofer N, et al. New insights into the biology of preeclampsia. Biol Reprod. 2006 May;74(5):772-776. Epub 2006 Jan. 